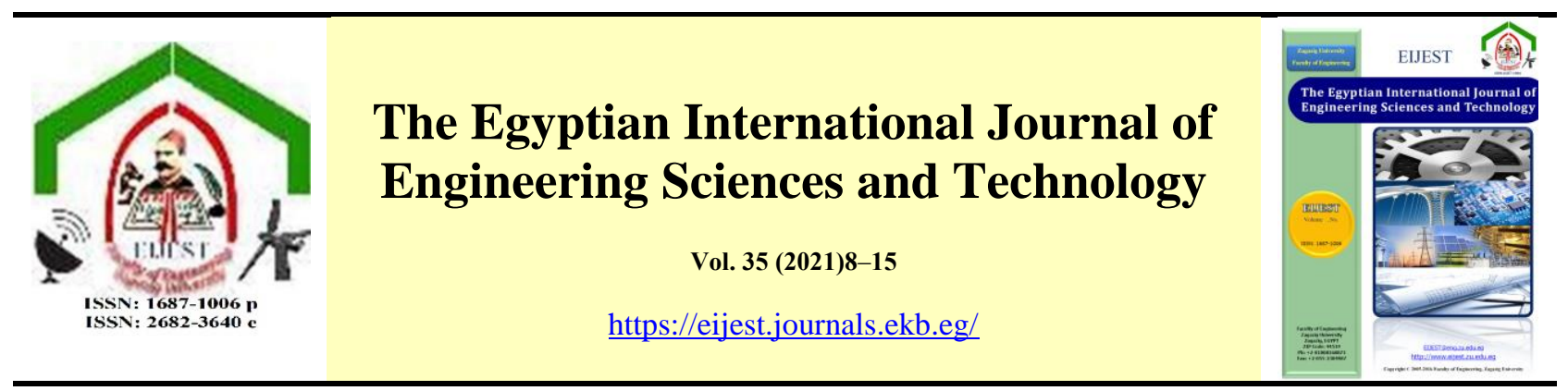

\title{
Compressive Strength of GUHPFRC Incorporating Fly Ash and Steel Fibers with Dissimilar Configuration
}

\author{
Sayed Ahmed ${ }^{\text {a }}$, Ramadan Asker ${ }^{\mathrm{b}}$, Dina Atef ${ }^{\mathrm{c}}$, Ayman Abdo ${ }^{\mathrm{d} *}$ \\ ${ }^{a}$ Lecturer., Structural Eng. Dep., Faculty of Engineering, Zagazig University, Egypt \\ ${ }^{b}$ Prof. of Structural Eng., Faculty of Engineering, Zagazig University, Egypt \\ ${ }^{c}$ B.cs, Structural Eng. Dep., Faculty of Engineering, Zagazig University, Egypt \\ ${ }^{d}$ Lecturer., Structural Eng. Dep., Faculty of Engineering, Zagazig University, Egypt \\ A R T I C L E I N F O \\ Keywords: \\ GUHPFRC \\ Fly Ash \\ Steel Fibers \\ Experimental Work. \begin{abstract}
A B S T R A C T
Nowadays, producing eco-friendly concretes by reducing the usage of high volumes of Portland cement is a global aim. Ultra-High Performance Fiber Reinforced Concrete (UHPFRC) involve using high volumes of Portland cement, which leads to high heat of hydration as well as high carbon emissions that enhance global warming. Therefore, researchers worldwide are interested in producing and assessing Green Ultra-High Performance Fiber Reinforced Concrete (GUHPFRC) which is the main focus of this paper. In this study, thirteen mixtures of such concretes are prepared to study the effect of using Fly Ash (FA) class F, as a Portland cement substitute by volume. The Fly Ash ratios of 15\%, 30\% and 45\% are used to study the effect on the compressive strength of UHPFRC. The paper also focuses on incorporating both corrugated and end hook steel Fibers in the mixes with ratios $(1 \%, 2 \%, 3 \%$ and $4 \%)$ to compensate for the decrease in compressive strength of concrete due to the replacement of cement by FA. The results showed that the substitution of $45 \%$ of the Portland cement with FA along with the incorporation of steel Fibers in the UHPFRC can be effective without any compressive strength loss.
\end{abstract}

\section{INTRODUCTION}

The concrete remains for many years the most widely used material with a worldwide supply of about 1 ton of concrete per person in the world [1]. For the continuous development of constructions, the continuous study of building materials is increasing concern of researchers over the time. These materials can significantly reduce energy consumption, conserve natural resources, and reduce carbon emission [1]. The building materials industries are mainly related to the extensive use of Ordinary Portland Cement (OPC) the associated release of excess carbon dioxide, and the severe damage that it causes [2].
During the last few decades the application of UHPFRC in the field of civil engineering has significantly increased [3]. However, to reach the ultra-high strength of the UHPFRC mixtures a high Portland cement content is needed (about twice that of conventional concrete). The high volumes of OPC incorporated in the UHPFRC composites produced high hydration heat and carbon dioxide concentrations that have major on the well-being of the world [4]. Therefore, continuous development in the use of lower amount of OPC in UHPFRC mixtures is indeed necessary. Accordingly, it is very important to develop green UHP-FRC with a low percentage of Portland cement by using Fly Ash as a replacement material fly ash [5]. The concept of

* Corresponding author. Tel.:+2-01001040132.

E-mail address: eng_a_abdo@yahoo.com. 
green concrete is a concrete that incorporates waste material, has high performance and life cycle sustainability, and does not result any environmental destruction during its production process. Since the cement industry accounts for eight- to 10 percent of the world's total emissions of carbon dioxide, it is highly necessary to use natural pozzolan or waste materials to manufacture environmentally sustainable concrete [6]. By using fly ash FA and the cementitious materials to partially replace cement in concrete also provides many environmental and technical advantages, such as preserving natural resources and reducing greenhouse gas emissions [6]. Aghdasi et al. [4] studied the effect of partially replacing the OPC with FA and 25\% ground granulated blast-furnace slag (GGBFS) on compressive, flexural and tensile strengths. Different types of micro and macro fibers were also added to the mixes. The results showed that, the addition of $25 \%$ FA and $25 \%$ GGBFS to partially replaced the cement by weight produced (GUHPFRC) mixtures had a compressive strength that exceeded $125 \mathrm{MPa}$ after 28 days. The incorporation of fibers into the UHPFRC mixture improved its ductility, tensile capacity, and the energy dissipation, and reduced cracks spacing. The impact of these variables is also a consequence of the ability to bond cementitious matrix-fiber, strength of fiber material, content of fiber volume, aspect ratio of fiber (length to diameter) and topology of fiber surface. The use of fiber in the mixture can provide tension strainhardening behaviour for the UHPFRC and also change the brittle behaviour to ductile behaviour [7, 8]. The effect of fibers with $1-4 \%$ of the concrete mixture volume on the UHPFRC mechanical properties was studied [9]. Tensile behaviour of UHPFRC before cracking is modelled by a linear elastic stress strain response. For the stage of after cracking, abi-linear tension-softening curve (TSC) based on the results of three-point bending test on notched prism specimens and inverse analysis was adopted [10]. The results show that the use of 3\% Fibers in the UHPFRC experienced higher compressive strength and elasticity modulus than 1 and $2 \%$.

The effect of fiber contents and shapes on the mechanical properties of UHPFRC were also studied [11]. Three fiber contents $(0,1,2$, and $3 \%)$ and three fiber shapes (hooked-end (HEF), corrugated fiber (CF), and straight fiber) were used. The results revealed that, UHPFRC flow ability steadily decreased as the fiber content increased and deformed fibers were used with high effects their compressive and flexural behaviours. At 28 days, compressive and flexural strengths of concrete reached over than 150 and $35 \mathrm{MPa}$, respectively when
$3 \%$ of the straight steel fibers were added. The 28 days compressive strengths of concrete with $3 \%$ HEF and 3\% CF improved by $48 \%$ and 59\% compared to that with straight fiber [12]. Therefore, fibers are now commonly used to improve the mechanical properties of concrete [13].

Steel end hook fibers improved UHPFRC compressive strength and bending performance compared with corrugated steel fibers, and end hook fibers had less impact compared to those with straight and corrugated fibers [14-15]. Whereas the use of a mixture of two different types of fibers is used to improve the behaviour of the fibrous bond and this is stimulated by increasing the strength of the fibers, increasing the density and strength of the mixture, and improving the mechanical bonding of the fibers through the deformation of the fibers [16-17]. According to these studies, and because of the different effects of steel fibers on the shape and mix of concrete and its effect on the mechanical properties of UHPFRC. Therefore, additional research on this topic will lead to new and complementary findings.

In this research, the production (using locally available materials) of Green Ultra High Performance fiber Reinforced Concrete (GUHPFRC) as an ecofriendly material with a partial replacement of cement with fly ash, considering the effect of steel fiber volume fraction content on compressive strength. In the GUHPFRC mixtures, the OPC is partially replaced by four percentage of the industrial FA class $\mathrm{F}(0,15 \%, 30 \%$ and $45 \%)$. Consequently, microsand, sand, silica fume, superplasticizer and combination of different types of fibers (HEF and $\mathrm{CF})$ with four percentages $(1 \%, 2 \%, 3 \%$, and $4 \%)$ was also used and the water/cement (W/C) was 0.20.

\section{RESEARCH SIGNIFICANCE}

This research focuses on studying the effect of substituting high volumes of Portland cement with Fly Ash to produce GUHPFRC, in effort to reduce the environmental impact caused by extended usage of Portland cement. Incorporating steel fibers in different proportions and dissimilar configurations, to eliminate the reduction in the compressive strength of UHPFRC is also addressed in the study.

\section{EXPERIMENTAL PROGRAM}

Cube specimens $100 \times 100 \times 100 \mathrm{~mm}$ are used in this research to study the effect of cement substitution with high volumes of FA on the compressive strength of UHPFRC 
1-Seventy-eight cubes are treated by Standard Water Curing method "submerged in water for 28 days".

2-Six standard cubes without any replacements or additions will be used as control specimens for comparison purposes.

\subsection{MATERIALS}

In this study, local OPC (type I $52.5 \mathrm{~N}$ ) was partially replaced with three FA percentages $(15 \%, 30 \%$ and $45 \%$ ). A poly- carboxylic based superplasticizer (type Sikament 163M complying to ASTM C494) was used to enhance the workability of GUHPFRC. Two sand sizes were used, normal sand (with the size from 1 to $2 \mathrm{~mm}$ ) and micro-sand (with the size from 0 to 1 $\mathrm{mm})$. For all mixes, silica fume was added by $5 \%$ of the cement content. The chemical and physical properties of OPC, SF, and FA are listed in Tables 1. The FA and SF confirm with the requirements of high active pozzolanic material according to ASTM C1240 [22]. Two different types of steel fiber (End hooked and Corrugated steel fiber) having an aspect ratio of 50 is used.

The parameters of the steel fibers are presented in Table 2. The deformation ratios of steel fibers were calculated based on Eq. (1) [21], and the results are listed in Table 2.

$$
R_{D}=\sum_{i} \frac{A_{b, i}}{A_{a, i}}
$$

In which, $i$ are the different sections of the half of the steel fiber; $A_{b, i}$ is the area of the bearing surface projected along the transverse axis of the fiber, in the section $i$; and $A_{a, i}$ is the area of the bearing surface projected along the longitudinal axis of the fiber, in the section $i$. Figure (1) shows the detailed of the used materials in this research. Figure (2) demonstrates the distributions of particle size for the products used.

\subsection{DESIGN}

The design of the UHPFRC mixture is based on the particle density used in the research. The performance of the concrete mixture can be increased by improving the filling densities of the component materials. A modified Andreasen and Andersen equation was used to design the UHPFRC mixtures proposed by Funk and Dinger [18], which are presented in Equation (2).

$$
\mathrm{PD}=\frac{D^{q}-D^{q} \min }{D^{q} \max -D^{q} \min }
$$

Where $\mathrm{P}$ (D) is a fraction of the total solids being smaller than size $D, D$ is the particle size $(\mu \mathrm{m}), D_{\max }$ is the maximum particle size $(\mu \mathrm{m}), \mathrm{D}_{\min }$ is the minimum particle size $(\mu \mathrm{m})$ and $\mathrm{q}$ is that the distribution modulus [18]. As a goal feature, the modified Andreasen and Andersen model (Equation (2)) serves to refine the structure of the mixture of granular materials in this work. The proportions of every substance in the mixture are determined separately until the optimum compatibility of the composite mixture is reached using an optimization algorithm based on the least squares method (LSM), as presented in the equation. (3).

$$
R S S=\sum_{i=n}^{n}\left(\operatorname{Pmix}\left(D i^{i+1}\right)-\operatorname{Ptar}\left(D i^{i+1}\right)\right)^{2}
$$

Once the deviation between the target curve and therefore the composed mix expressed by the summation of the squares of the residuals (RSS) at means particle sizes is minimized, the composition of the concrete is treated similarly to the best one [19]. where Pmix is that the composed combine and Ptar is that the target grading calculated from Equation (2).

Table 1: Chemical and physical properties of OPC, SF and FA.

\begin{tabular}{|c|c|c|c|}
\hline Item & OPC & SF & FA \\
\hline $\mathrm{SiO}_{2}$ & 20.1 & 92.26 & 62.32 \\
\hline $\mathrm{Al}_{2} \mathrm{O}_{3}$ & 5.62 & 0.89 & $23 . .95$ \\
\hline $\mathrm{Fe}_{2} \mathrm{O}_{3}$ & 2.17 & 1.97 & 1.33 \\
\hline $\mathrm{CaO}$ & 62.92 & 0.49 & 4.74 \\
\hline $\mathrm{MgO}$ & 1.14 & 0.96 & 2.04 \\
\hline $\mathrm{Cl}$ & 0.0096 & 0.009 & - \\
\hline $\mathrm{SO}_{3}$ & 2.92 & 0.33 & 1.25 \\
\hline $\mathrm{Na}_{2} \mathrm{O}$ & 0.3 & 0.42 & - \\
\hline $\mathrm{K}_{2} \mathrm{O}$ & 0.85 & 1.31 & 0.76 \\
\hline $\mathrm{LOI}$ & 3.84 & - & 3.12 \\
\hline $\mathrm{S} . \mathrm{D}$ & 3150 & 2200 & 2130 \\
\hline
\end{tabular}

$\mathrm{S} . \mathrm{D}=$ Specific density $\left(\mathrm{kg} / \mathrm{m}^{3}\right)$.

Table 2: Physical properties of steel fiber.

\begin{tabular}{|l|c|c|c|c|c|c|}
\hline Item & Type & S.D & $\mathrm{L} \mathrm{mm}$ & $\mathrm{D} \mathrm{mm}$ & $\mathrm{AR}$ & $f_{t}, \mathrm{MPa}$ \\
\hline Hooked End & Round & 7.8 & 50 & 1 & 50 & $\begin{array}{c}1000: \\
1500\end{array}$ \\
\hline Corrugated & Round & 7.8 & 50 & 1 & 50 & $\begin{array}{c}1000: \\
1500\end{array}$ \\
\hline
\end{tabular}

$\mathrm{S} . \mathrm{D}=$ Specific density $\left(\mathrm{t} / \mathrm{m}^{3}\right)$, L=Length, $\mathrm{D}=$ Diameter, $\mathrm{AR}=$ Aspect ratio, $f_{t}=$ Tensile Strength

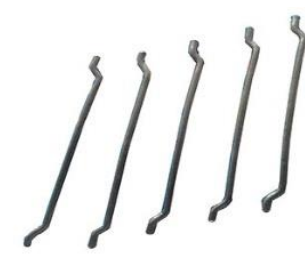

Hooked end

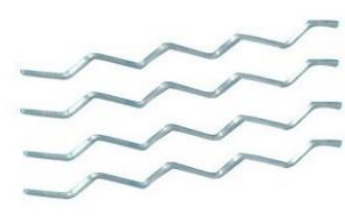

Corrugated

Fig.1: Shape of Steel Fibers. 


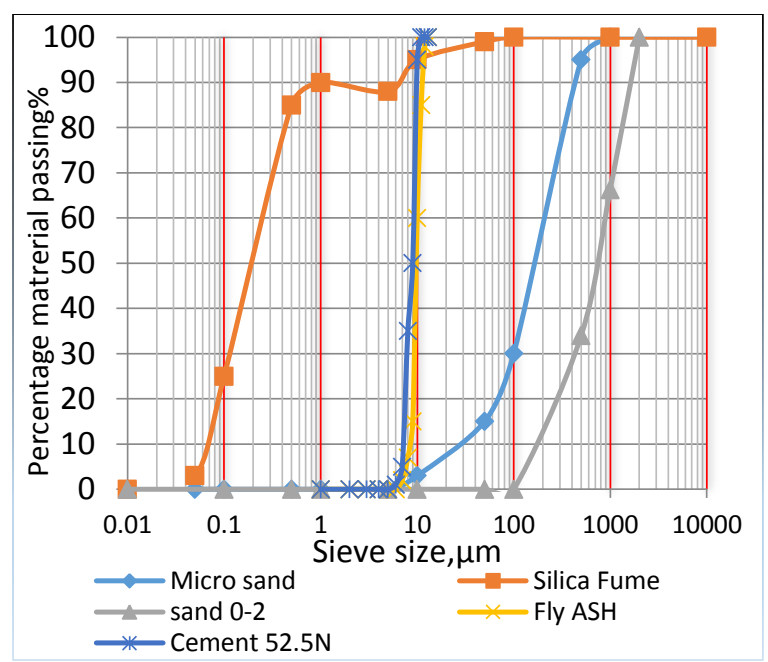

Fig.2. Particle size distribution of the used materials [19].

In this research, the UHPFRC and GUHPFRC mixtures are listed in Table 3. Twelve different mixtures of G-UHP-FRC and one type of UHPFRC used as a control mix are designed. The concrete mixture UHPFRC has high cement content (about $874.9 \mathrm{~kg} / \mathrm{m}^{3}$ ) while 12 mixtures of GUHPFRC $15 \%$, $30 \%$ and $45 \%$ of cement are replaced by fly ash FA to study the effect of fly ash in these mixtures. Although the raw material contents as sand, microsand, silica fume, superplasticizer and water content are similar in each mixture. Additionally, the fiber content is about $1 \%-4 \%$ by volume add to mix concrete. Hence, in this study, to investigate the effect of fibers on the properties of G-UHP-FRC, the steel fibers are added into each G-UHP-FRC mixes in the amount of $1 \%, 2 \%, 3 \%$, and $4 \%$ (by the volume add to concrete). Table 3 clearly shows that the control mix and the twelve GUHPFRC mix in details.

\subsection{MIXING AND CURING}

A mixing procedure proposed in the literature was adopted for the preparation of UHPFRC in this study, where in all powder and sand fractions are mixed along for $10 \mathrm{~min}$, after that about $70 \%$ mixing water put in to the blend of dry constituents for $7 \mathrm{~min}$ mixing and we adding remaining water and $30 \%$ superplasticizer are adding to mix and still mixing 5 min then add other 30\% Superplasticizer and mixing 3 min, finally add remaining of Superplasticizer and still mixing $5 \mathrm{~min}$ until the mixture became homogeneity, and also in GUHPFRC the same mixing in UHPFRC then adding steel fiber after homogeneous of the mixture. Seventy-eight cube specimens of dimensions [100 mm length, $100 \mathrm{~mm}$ width and $100 \mathrm{~mm}$ height] were cast to examine the compressive strength. All the casted specimens were demolded after $24 \mathrm{~h}$ and placed in water at room temperature for normal curing until the day of testing. The Compressive strength testing of the specimens is shown in Figure (3).

Table 3: Mixture Proportions of UHPFRC.

\begin{tabular}{|c|c|c|c|c|c|c|c|c|c|c|}
\hline \multirow{2}{*}{$\begin{array}{l}\text { Mix } \\
\text { ID }\end{array}$} & \multicolumn{8}{|c|}{ Mix components $\left(\mathrm{kg} / \mathrm{m}^{3}\right)$} & \multirow[b]{2}{*}{$\begin{array}{l}\text { StF } \\
(\%)\end{array}$} & \multirow[b]{2}{*}{$\begin{array}{l}\text { FA } \\
(\%)\end{array}$} \\
\hline & \begin{tabular}{|c|}
$\mathrm{C}$ \\
$(\mathrm{kg})$
\end{tabular} & $\begin{array}{c}\mathrm{SF} \\
(\mathrm{kg})\end{array}$ & \begin{tabular}{|c} 
Sand \\
$0-1 \mathrm{~mm}$ \\
$(\mathrm{~kg})$ \\
\end{tabular} & \begin{tabular}{|c|} 
Sand \\
$0-2 \mathrm{~m}$ \\
$(\mathrm{~kg})$ \\
\end{tabular} & $\begin{array}{c}\text { SP } \\
(\mathrm{kg})\end{array}$ & $\begin{array}{c}\mathrm{W} \\
(\mathrm{kg})\end{array}$ & $\begin{array}{l}\mathrm{StF} \\
(\mathrm{kg})\end{array}$ & $\begin{array}{c}\text { FA } \\
(\mathrm{kg})\end{array}$ & & \\
\hline Control & 875 & 43.7 & 218.7 & 1054.7 & 46 & 184 & 0 & 0 & 0 & 0 \\
\hline Mix 1 & 744 & \multirow{4}{*}{43.7} & \multirow{4}{*}{218.7} & \multirow{4}{*}{1054.7} & \multirow{4}{*}{46} & \multirow{4}{*}{184} & 78 & \multirow{4}{*}{-131} & 1 & \multirow{4}{*}{15} \\
\hline Mix 2 & 744 & & & & & & 156 & & 2 & \\
\hline Mix 3 & 744 & & & & & & 234 & & 3 & \\
\hline $\operatorname{Mix} 4$ & 744 & & & & & & 312 & & 4 & \\
\hline Mix 5 & 612 & \multirow{4}{*}{43.7} & \multirow{4}{*}{218.7} & \multirow{4}{*}{1054.7} & \multirow{4}{*}{46} & \multirow{4}{*}{184} & 78 & \multirow{4}{*}{262} & 1 & \multirow{4}{*}{30} \\
\hline Mix 6 & 612 & & & & & & 156 & & 2 & \\
\hline Mix 7 & 612 & & & & & & 234 & & 3 & \\
\hline Mix 8 & 612 & & & & & & 312 & & 4 & \\
\hline Mix 9 & 481 & \multirow{4}{*}{43.7} & \multirow{4}{*}{218.7} & \multirow{4}{*}{1054.7} & \multirow{4}{*}{46} & \multirow{4}{*}{184} & 78 & \multirow{4}{*}{393} & 1 & \multirow{4}{*}{45} \\
\hline Mix 10 & 481 & & & & & & 156 & & 2 & \\
\hline Mix 11 & 481 & & & & & & 234 & & 3 & \\
\hline Mix 12 & 481 & & & & & & 312 & & 4 & \\
\hline
\end{tabular}

C: cement, SF: silica fume, SP: superplasticizer, StF: steel fiber, and FA: fly ash

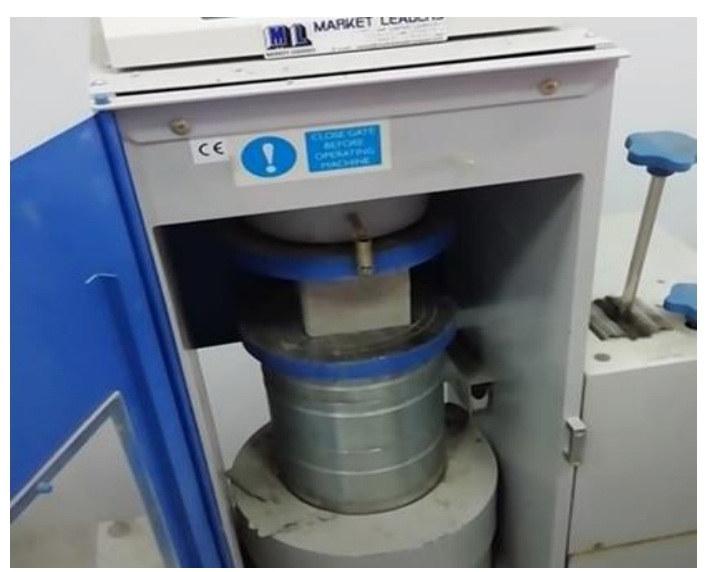

Fig. 3. Sample of Cubes Under Compressive Force.

\subsection{Testing Methods}

The compressive strength test was performed on seventy-eight of the standard test cubes to standard specifications to obtain the compressive strength of concrete cubes specimens. The cubes were loaded in 
a testing machine under load control at the rate of 0.3 $\mathrm{MPa} / \mathrm{sec}$ until failure.

\section{RESULTS AND DISCUSSION}

Experimental results were presented for the 13 mixtures of concrete previously shown in Table 3. Each mixture contains 6 cubes of the same materials proportions. The first mixture is a control mixture that obtained to use a base in the comparison of the compressive strength of the other 12 mixtures. The effect of FA and steel fibers percentage on the concrete compressive strength at 7 and 28 days is presented in Table 4. The percentage increase/decreases in the concrete compressive strength at 7 and 28 days $(\Delta 7 \%$ and $\Delta 28 \%)$, respectively and the enhancement in concrete compressive strength as the curing time increased from 7 to 28 days are also presented in Table 4 . According to ASTM C1856/C1856M, the UHPC mixtures must have compressive strength more than $120 \mathrm{MPa}$. When compared with the results in table with ASTM C1856/C1856M it is introduced that the control mixture and mixture 1, 2, 9, 10, 11 and 12 are HPC and form mixture 3 to 8 are UHPC as showed in Table 4.

Table 4: Compressive Strength (MPa)

\begin{tabular}{|c|c|c|c|c|c|c|}
\hline ID & $\mathrm{F}_{\text {cu7 }}$ & $\mathrm{F}_{\text {cu2 } 8}$ & $\Delta_{7} \%$ & $\Delta_{28} \%$ & $\Delta_{28 / 7} \%$ & Type \\
\hline Control & 71.0 & 96.0 & $0 \%$ & $0 \%$ & $35.21 \%$ & HPC \\
\hline Mix 1 & 73.5 & 101.0 & $3.52 \%$ & $5.21 \%$ & $37.41 \%$ & HPC \\
\hline Mix 2 & 76.0 & 102.0 & $7.04 \%$ & $6.25 \%$ & $34.21 \%$ & HPC \\
\hline Mix 3 & 79.3 & 121.0 & $11.69 \%$ & $26.04 \%$ & $52.59 \%$ & UHPC \\
\hline Mix 4 & 79.7 & 134.0 & $12.25 \%$ & $39.58 \%$ & $68.13 \%$ & UHPC \\
\hline Mix 5 & 79.0 & 123.0 & $11.27 \%$ & $28.13 \%$ & $55.70 \%$ & UHPC \\
\hline Mix 6 & 80.3 & 128.0 & $13.10 \%$ & $33.33 \%$ & $59.40 \%$ & UHPC \\
\hline Mix 7 & 81.5 & 125.0 & $14.79 \%$ & $30.21 \%$ & $53.37 \%$ & UHPC \\
\hline Mix 8 & 81.8 & 138.0 & $15.21 \%$ & $43.75 \%$ & $68.70 \%$ & UHPC \\
\hline Mix 9 & 51.0 & 98.0 & $-28.1 \%$ & $2.08 \%$ & $92.16 \%$ & HPC \\
\hline Mix 10 & 51.5 & 117.0 & $-27.4 \%$ & $21.88 \%$ & $127.18 \%$ & HPC \\
\hline Mix 11 & 50.0 & 90.0 & $-29.5 \%$ & $-6.25 \%$ & $80.00 \%$ & HPC \\
\hline Mix 12 & 52.0 & 108.0 & $-26.7 \%$ & $12.50 \%$ & $107.69 \%$ & HPC \\
\hline
\end{tabular}

\subsection{EFFECT OF FLY ASH}

Figure (4) shows the compressive strength values acquired after 7 and 28 days of tested samples integrated different proportions of FA $(15 \%, 30 \%$ and $45 \%$ ). In general, increasing the curing time from 7 to 28 days enhanced the UHPFRC compressive strength. At $1 \%, 2 \%, 3 \%$ and $4 \%$ addition of steel fibers, the UHPFRC compressive strength increased by $37.41 \%, 34.21 \%, 52.59 \%$, and $68.13 \%$ respectively for $\mathrm{FA}=15 \%$. Consequently, for $\mathrm{FA}=30 \%$, the UHPFRC compressive strength increased by $55.7 \%, 59.4 \%, 53.37 \%$ and $68.7 \%$. Moreover, for $\mathrm{FA}=45 \%$, the UHPFRC compressive strength increased by $92.16 \%, 127.18 \%, 80 \%$ and $107.69 \%$. In addition, as the FA\% increased up to $30 \%$, the UHPFRC compressive strength increased at all the steel fibers percentages. When the FA\% increased to $30 \%$, the UHPFRC compressive strength increased by $11.95 \%, 11.07 \%, 0.27 \%$, and $9.5 \%$ for the four steel fibers ratios. This assured FA effects on decreasing the concrete voids thus enhanced the UHPFRC compressive strength. In contrast, increasing the FA\% to $45 \%$ decreased the compressive strength for all the steel fibers contents. As the FA\% increased from $30 \%$ to $45 \%$, the UHPFRC strength decreased by $18.23 \%, 10.16 \%$, $29.94 \%$, and $27.05 \%$. The increase of the FA\% to $45 \%$ may be badly affected the cementitious hydration. When comparing these results with the standard samples, it is found that the use of fly ash with different percentages of fibers gives good results compared to standard cubes, as it reached the best results when the fiber content reaches $4 \%$ of the volume of concrete and $30 \%$ of the replacement ratio of cement with fly ash, where the compression strength increased in concrete by $43.75 \%$. Including high volumes of fly ash together with steel fibers lead to large reductions in use of Portland cement. Accordingly reducing the harmful effects on the e environment. Therefore, mixtures that has 28 days' compressive strength above the dash-dot line in figure 4 is UHPC according to ASTM $\mathrm{C} 1856 / \mathrm{C} 1856 \mathrm{M}$ and below it is HPC.

\subsection{EFFECT OF STEEL FIBERS}

Figure (5) shows the compressive strength values acquired during 7 and 28 days of tested samples integrated different proportions of steel fiber (SF) $(1 \%, 2 \%, 3 \%$ and $4 \%)$. In general, increasing the curing time from 7 to 28 days enhanced the UHPFRC compressive strength. At 15\%, 30\%, and 45\% fly ash replacement, the UHPFRC compressive strength increased by $37.41 \%, 55.7 \%$, and $92.16 \%$ respectively for $\mathrm{SF}=1 \%$. Consequently, for $\mathrm{SF}=2 \%$, the UHPFRC compressive strength increased by $34.41 \%, 59.4 \%$, and $127.18 \%$ as the fly ash were integrated to the mixes by $15 \%, 30 \%$ and $45 \%$, respectively. For $\mathrm{SF}=3 \%$, the UHPFRC compressive strength increased by $52.59 \%, 53.37 \%$, and $80 \%$. Moreover, for $\mathrm{SF}=4 \%$, the UHPFRC compressive strength increased by $68.13 \%, 68.7 \%$ and $107.69 \%$. 
Conversely, as the SF\% increased up to $4 \%$, the UHPFRC compressive strength increased at all the fly ash percentages.

In general, the UHPFRC compressive strength of the samples increases with increasing the steel fibers percentage and the concrete age. But what it became clear to us in this research is that with increasing cement replacement percentage by more than $30 \%$, compressive strength decreased despite its higher

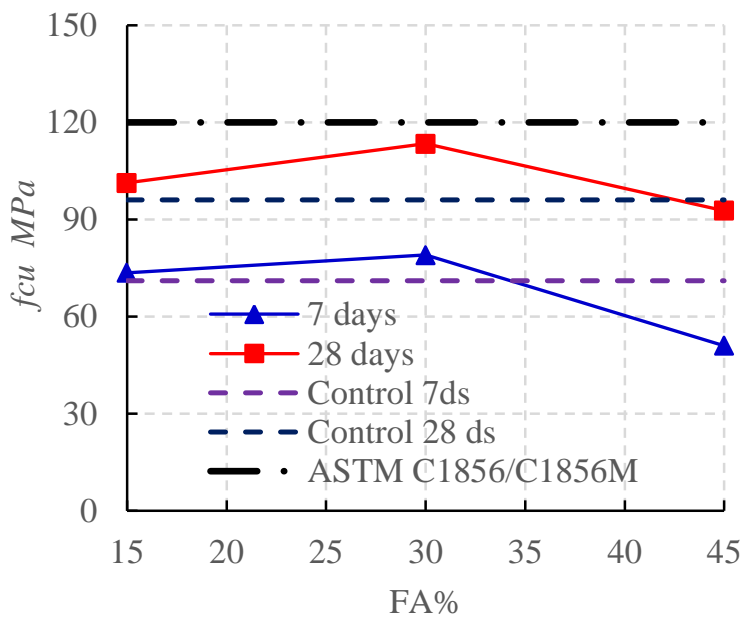

a) Steel fiber $=1 \%$

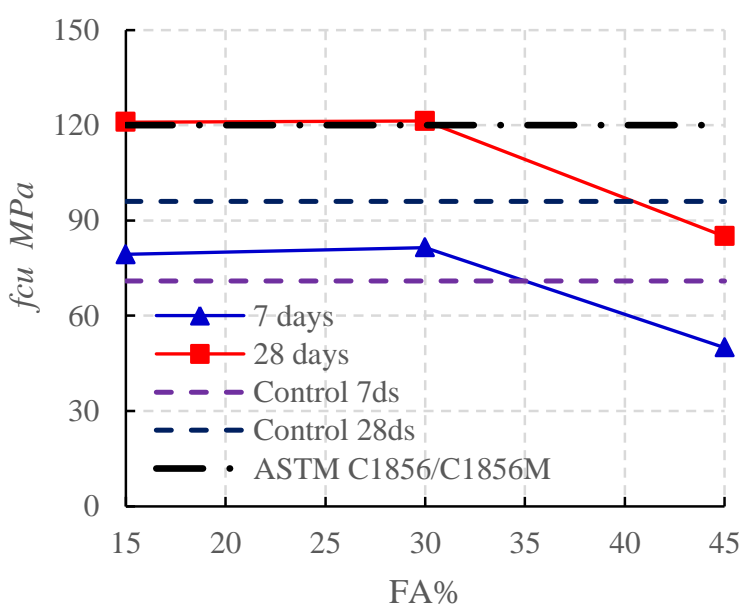

c) Steel fiber $=3 \%$ fiber content at 7 and 28 days. It is also evident that the replacement percentage of cement $30 \%$ and the fiber rate of $4 \%$ gave the highest pressure resistance in this study, as it increased by $43.75 \%$ over the reference concrete cubes. Therefore, mixtures that has 28 days' compressive strength above the dash-dot line in figure 5 is UHPC according to ASTM $\mathrm{C} 1856 / \mathrm{C} 1856 \mathrm{M}$ and below it is HPC.

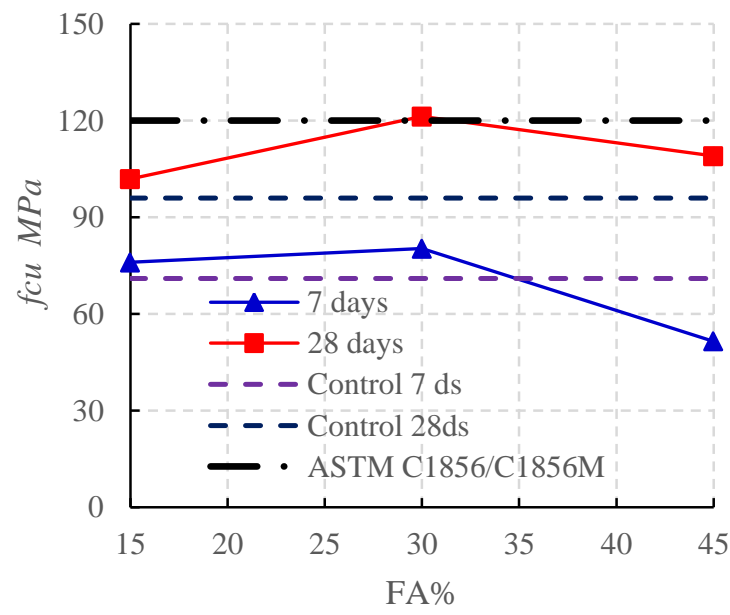

b) Steel fiber $=2 \%$

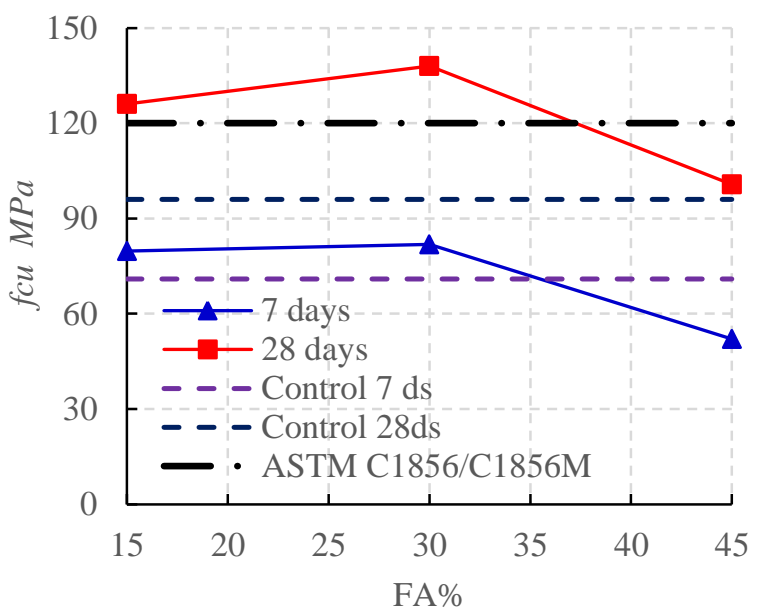

d) Steel fiber $=4 \%$

Fig. 4. Effect of fly ash content on compressive strength of UHPFRC. 


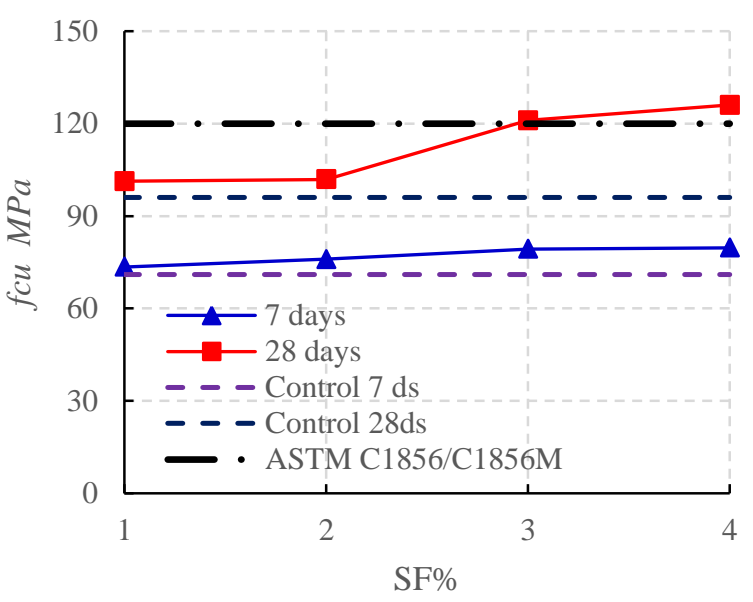

a) Fly ash $=15 \%$

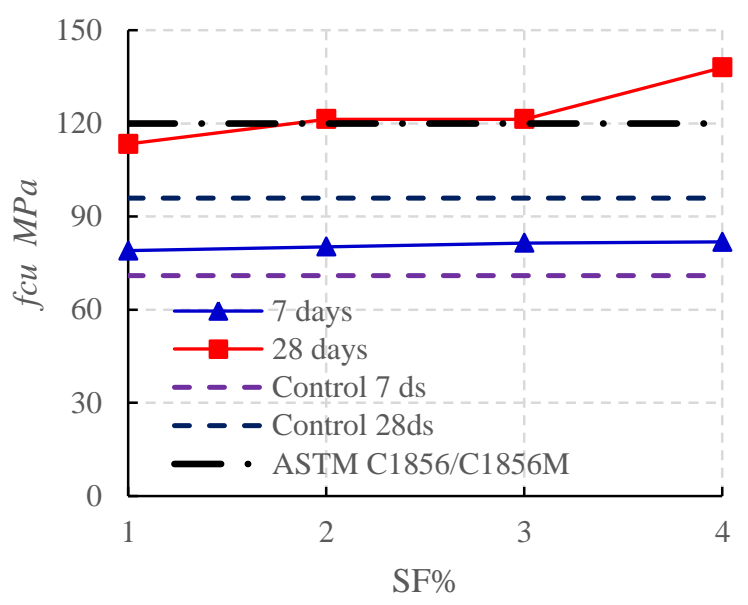

b) Fly ash $=30 \%$

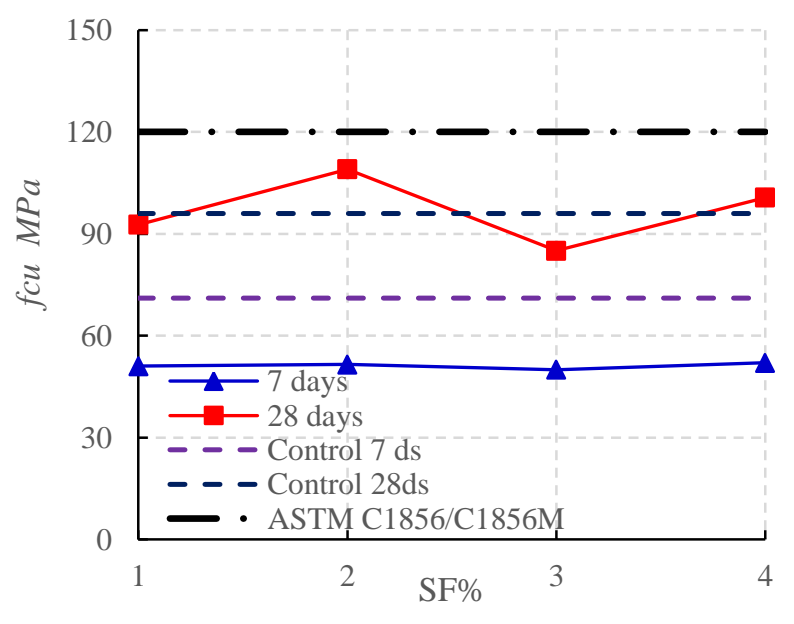

c) Fly ash $=45 \%$

Fig. 5. Effect of steel fiber content on compressive strength of UHPFRC.

\section{CONCLUSIONS}

This experimental research work to produce GUHPFRC to meet the compressive strength specifications of ASTM C1240 using three different ratios of fly ash replacements $15 \%, 30 \%$ and $45 \%$ for cement substitution. These different ratios of FA are $15 \%, 30 \%$ and $45 \%$. Additional steel fibers of $1 \%$, $2 \%, 3 \%$ and $4 \%$ from the UHPFRC volume were added to mix concrete. The following conclusions were drawn from laboratory tests:

1- As the FA\% increased from $15 \%$ to $30 \%$, the UHPFRC compressive strength increased by $11.95 \%, 11.07 \%, 0.27 \%$, and $9.5 \%$ as the steel Fibers were integrated to the mixes by $1 \%, 2 \%$, $3 \%$ and $4 \%$, respectively. The effects of FA on decreasing the concrete voids thus enhanced the UHPFRC compressive strength. In contrast, increasing the FA\% to $45 \%$ decreased the strength whatever the steel Fibers contents by $18.23 \%$, $10.16 \%, 29.94 \%$, and $27.05 \%$.

2- The UHPFRC compressive strength of the mixtures increases with the increase in the proportion of steel Fibers and the age of concrete, reaching the highest level at $4 \%$.

3 - The environmental compatibility of the mixtures is assessed by the large disposal rate of cement and its replacement with environmentally friendly materials, which occurs when the highest percentage of fly ash is reached, which is $45 \%$, but what results in a loss of a percentage of the compressive strength of the concrete. For this, 
proportions of steel Fibers were used to compensate the loss of the compressive strength ratios.

4-By comparing these findings to the standard tests, it is discovered that using fly ash with various amounts of Fibers produces good results when compared to reference concrete cubes. The best results occurring when the Fibers content reached $4 \%$ of the volume of concrete and $30 \%$ of the cement substitution ratio with fly ash, resulting in a $43.75 \%$ improvement in UHPFRC compressive strength.

5-From these results some mixtures yielded results GUHPFRC and other mixtures don't reach to the required compressive strength and it classified as GHPFRC.

\section{REFERENCES}

[1] A. M. Mhaya, G. F. Huseien, A. R. Z. Abidin and M. Ismail, "Long-term mechanical and durable properties of waste tires rubber crumbs replaced GBFS modified concretes", Constr. Build. Mater, 256 (2020) 119505, https://doi.org/10.1016/j. conbuildmat.2020.119505.

[2] S. Vatannia, E. Kearsley and D. Mostert, "Development of economic, practical and green ultra-high performance Fiber reinforced concrete verified by particle packing model", Case Stud. Constr. Mater, 13 (2020) e00415, https://doi.org/10. 1016/j.cscm.2020.e00415.

[3] C. P. Gu, G. Ye and W. Sun, "Ultrahigh performance concreteproperties", Applications and perspectives. Sci. China Technol. Sci., Vol. 58, 2015, pp 587-599, https://doi.org/10.1007/ s11431-015-5769-4.

[4] P. Aghdasi and C. P. Ostertag, "Green ultra-high performance Fiber-reinforced concrete (G-UHP-FRC)", Constr. Build. Mater, Vol. 190, 2018, pp. 246-254, https://doi.org/10.1016/ j.conbuildmat.2018.09.111.

[5] V. Vishwakarma and D. Ramachandran, Green Concrete mix using solid waste and nanoparticles as alternatives - A review", Constr. Build. Mater, Vol. 162, 2018, pp. 96-103, https://doi. org/10.1016/j.conbuildmat.2017.11.174.

[6] B. Suhendro, "Toward green concrete for better sustainable environment", Procedia Eng., Vol. 95, 2014, pp. 305-320, https://doi.org/10.1016/j.proeng.2014.12.190.

[7] F. Moghaddam, V. Sirivivatnanon and K. Vessalas, "The effect of fly ash fineness on heat of hydration, microstructure, flow and compressive strength of blended cement pastes", Case Stud. Constr. Mater, 10 (2019) e00218, https://doi.org/10.1016/j. cscm.2019.e00218.

[8] G. D. Ashkezari, F. Fotouhi and M. Razmara, "Experimental relationships between steel Fiber volume fraction and mechanical properties of ultra-high performance Fiberreinforced concrete", Journal of Build. Eng., 32 (2020) 101613 https://doi.org/10.1016/j.jobe.2020.101613.

[9] K. Wille, A. E. Naaman, S. El-Tawil and G. J. ParraMontesinos, "Ultra-high performance concrete and Fiber reinforced concrete: Achieving strength and ductility without heat curing. Mater", Struct. Constr., Vol. 45, 2012, pp. 309324, https://doi. org/10.1617/s11527-011-9767-0.
[10] R. Solhmirzaei and V. R. Kodur, "Modeling the response of ultra-high performance Fiber reinforced concrete beams. Constr", Procedia Engineering, Vol. 210, 2017, pp. 211-219, https://doi.org/10.1016/j.proeng.2017.11.068

[11] D. Y. Yoo, J. H.Lee and Y. S. Yoon, "Effect of Fiber content on mechanical and fracture properties of ultra-high performance Fiber reinforced cementitious composites", Compos. Struct., Vol. 106, 2013, pp. 742-753, https://doi.org/10.1016/j. compstruct.2013.07.033

[12] Z. Wu, C. Shi, W. He and L. Wu, "Effects of steel Fiber content and shape on mechanical properties of ultra-high performance concrete" Constr. Build. Mater, Vol. 103, 2016, pp. 8-14, https://doi.org/10.1016/j.conbuildmat.2015.11.028

[13] Ş.Yazici, G. Inan and V. Tabak, "Effect of aspect ratio and volume fraction of steel Fiber on the mechanical properties of SFRC", Constr. Build. Mater, Vol. 21, 2007, pp. 1250-1253, https://doi. org/10.1016/j.conbuildmat.2006.05.025.

[14] J. Liu, F.Han, G. Cui, Q. Zhang, J. Lv, L. Zhang and Z. Yang, "Combined effect of coarse aggregate and Fiber on tensile behaviour of ultra-high performance concrete", Constr. Build. Mater, Vol. 121, 2016, pp. 310-318, https://doi.org/10.1016/ j.conbuildmat.2016.05.039.

[15] B. Li, L. Xu, Y. Shi, Y. Chi, Q. Liu and C. Li, "Effects of Fiber type, volume fraction and aspect ratio on the flexural and acoustic emission behaviours of steel Fiber reinforced concrete", Constr. Build. Mater, Vol. 181, 2018, pp. 474-486, https://doi.org/10.1016/j.conbuildmat.2018.06.065.

[16] P. Mahakavi and R. Chithra, "Impact resistance, microstructures and digital image processing on selfcompacting concrete with hooked end and crimped steel Fiber", Constr. Build. Mater, Vol. 220, 2019, pp. 651-666, https://doi.org/10.1016/j.conbuildmat. 2019.06.001.

[17] K. Wille, D. J. Kim and A. E. Naaman, "Strain-hardening UHP-FRC with low Fiber contents", Mater. Struct. Constr., Vol. 44, 2011, pp. 583-598, https://doi.org/10.1617/s11527010-9650-4.

[18] G. Gautham, K. Reddy and P. Ramadoss, "Influence of alccofine incorporation on the mechanical behaviour of ultrahigh performance concrete (UHPC)", Mater. Today Proc., Vol. 33, 2020, pp. 789-797, https://doi.org/10.1016/j.matpr.2020. 06. 180.

[19] R. Yu, P. Spiesz and H. J. H. Brouwers," Mix design and properties assessment of Ultra-High Performance Fiber Reinforced Concrete (UHPFRC)", Cem. Concr. Res., Vol. 56, 2014, pp. 29-39, https://doi.org/10.1016/j.cemconres.2013. 11.002.

[20] H. A. Mohamed, "Effect of fly ash and silica fume on compressive strength of self-compacting concrete under different curing conditions", Ain Shams Eng. J., Vol. 2, 2011, pp. 79-86, https://doi.org/10.1016/j.asej.2011.06.001.

[21] Y. Liu, Z. Zhang, C. Shi, D. Zhu, N. Li and Y. Deng, "Development of ultra-high performance geopolymer concrete (UHPGC)", Cement and Concrete Composites, 112 (2020) 103670, https://doi.org/10.1016/j.cemconcomp.2020.103670.

[22] ASTM International, Standard Specification for Silica Fume Used in Cementitious Mixtures, Designation: C1240, ASTM International, West Conshohocken, PA, 2015, https://doi. org/10.1520/C1240-15. 